\title{
Análise dos Programas de Interiores Moderno nos Anúncios Publicados Pela Mobília Contemporânea na Revista Casa \& Jardim Anos 1959 e 1960
}

Analysis of Modern Interior Programs in the Announcements Published by the Mobilia Contemporânea in the 1959 and 1960 Casa\&Jardim Magazine

MITIDIERI, Raíssa Cristina; Bacharel; UNISO

raissa_mitidieri@hotmail.com

BRAGA, Marcos da Costa; Doutor em História Social; FAU USP

bragamcb@usp.br

\section{Resumo}

O presente artigo tem como objetivo analisar os anúncios da Mobília Contemporânea publicados nas edições da Revista Casa \& Jardim no recorte temporal de 1959 e 1960. A análise teve embasamento nos conceitos de arranjos e ambiência definidos pelo sociólogo Jean Baudrillard em O Sistema dos Objetos em conjunto com a autora Martine Joly para análise das imagens dos ambientes. Os estudos realizados dos anúncios revelam uma visão da relação da Mobília Contemporânea com o cliente, na qual eram ofertadas inúmeras maneiras de organização do ambiente moderno. A loja se desenvolveu com o passar dos anos, visto que sua essência e ideal de produzir e vender móveis de qualidade de maneira eficiente era constante nos vinte anos de vida da Mobília Contemporânea.

Palavras Chave: Mobília Contemporânea; ambiente moderno; anúncios modernos.

\begin{abstract}
The present article aims to analyze the advertisements of Mobilia Contemporânea published in the editions of the magazine Casa \& Jardim in the temporal cut of 1959 and 1960. The analysis was based on the concepts of arrangements and ambience defined by the sociologist Jean Baudrillard in The System of Objects together with the author Martine Joly to analyze the images of the environments. The studies carried out in the advertisements reveal a vision of the relationship of the Mobilia Contemporânea with the client, in which innumerable ways of organizing the modern environment were offered. The store has developed over the years, since its essence and ideal of producing and selling quality furniture efficiently was constant in the twenty years of the Mobilia Contemporânea.
\end{abstract}

Keywords: Mobilia Contemporânea; modern room; modern advertising. 


\section{Introdução}

Este trabalho irá estudar e analisar os conceitos dos programas de interiores criados por Michel Arnoult na Mobília Contemporânea (MC). A empresa teve filiais em São Paulo e Rio de Janeiro e se firmou com a produção em série de mobiliários em um momento que o Brasil vivia o auge do movimento moderno onde a arquitetura era uma das protagonistas e o avanço do processo de industrialização no país se desenvolvia. Nosso recorte se inicia nos anos 1950, época em que Arnoult deu abertura à sua carreira no Brasil, ${ }^{1}$ com desenhos autorais de mobiliários modernos, e inaugurou a primeira fábrica em Curitiba, até 1974, onde a MC encerrou suas atividades no mercado.A Mobília Contemporânea tinha como objetivo atingir variadas camadas sociais através da popularização do conceito, produção e venda do design, através da criação de móveis de qualidade e acessíveis financeiramente às camadas populares, com a premissa de que eles não necessitariam ser sinônimo de mobiliário de baixa qualidade ruim. Se introduziram no mercado utilizando linhas de programas de interiores de salas, quartos e escritórios, foram pioneiros ao implementar o uso de maquetes na loja como artifício de marketing. Utilizaram pontos estratégicos para comercialização e modos facilitadores de transporte e montagem do produto. $\mathrm{O}$ objetivo do artigo é identificar e analisar a concepção dos arranjos e ambiência dos ambientes modernos por meio dos anúncios e imagens dos programas de interiores elaboradores pela Mobília Contemporânea publicados na revista Casa \& Jardim, fase em que a MC introduziu móveis desmontáveis e adaptáveis para diferentes ambientes. As fontes são a historiografia publicada sobre a Mobília Contemporânea e as noções de arranjos e ambiência das moradias modernas de Baudrillard (1968) e a análise de imagem proposta por Joly (1996).

\section{A Consolidação do Design Moderno no Brasil}

Precursora da modernidade, a arquitetura moderna toma seu espaço e evidência inicialmente através das casas de Gregori Warchavchik. Inspirada na máquina e na indústria, Warchavichik entendia a casa como uma máquina de morar, uma vez que, através da industrialização a arquitetura poderia alcançar sua função social. Em 1930 organizou a "Exposição de uma Casa Modernista" em sua residência onde a abriu para expor seu interior totalmente moderno; mobiliários funcionais de linhas retas e cores claras, e pinturas de artistas como Tarsila do Amaral embelezavam as paredes.

Nos anos 1930 o mobiliário e as construções eram rebuscadas de adornos - Art Déco, que contracenava com o ecletismo, logo é marcado pelos primeiros passos da aceitação do móvel moderno, principalmente a elite que seguiu adequando suas residências aos novos padrões da arquitetura moderna. O Brasil durante esta época recebeu muitos arquitetos estrangeiros que alavancaram o novo desenho de mobiliário no país. Porém, quem se destacou foi Joaquim Tenreiro artesão da madeira que deu novos ares ao móvel, porém os materiais eram produzidos com madeiras de lei, sobretudo o Jacarandá, sempre presente nas casas de classes mais altas, e com um desenho moderno refinado. Foram tempos de descobertas e desenvolvimento no móvel marcado pela busca por insumos rústicos e que tivessem identidade nacional, como fibras de caroá, cânhamo, palhinha, juta, sisal entre outros.

O Brasil seguia em um crescente caminho para a industrialização, junto do intenso processo de verticalização urbana dos anos 1940 e 1950. Nas principais cidades, como Rio de Janeiro e São Paulo, muitos prédios estavam sendo construídos, era um mercado promissor para

\footnotetext{
${ }^{1}$ Michel Arnoult chegou ao Brasil, no Rio de Janeiro em 1950 com 28 anos de idade.
} 
arquitetos e designers. Em uma crônica publicada, Rubem Braga diz: "Mas em volta de mim, sobre meu peito, e sobre meu ventre, resolveram construir uma cidade. Incorporações, edifícios de apartamentos, quarto e sala, kitchenette, entrada de dez por cento". O autor fazia referência às novas construções como cubos de concreto, por possuírem pequenas áreas construídas e serem erguidas através do concreto armado (LEON, 2016: 36).

Na mesma época Arnoult chega ao Brasil, com ideias de desenho e produção de móveis para atingir as novas classes urbanas que estavam surgindo com a verticalização da cidade.

\section{Michel Arnoult e Sócios na Mobília Contemporânea}

Natural de Paris, Michel Arnoult chegou ao Brasil em 1950, no Rio de Janeiro, formado em desenho industrial pelo Centro Artístico Técnico da Escola de Camondo. Imediatamente foi contratado por Oscar Niemeyer para trabalhar em seu escritório. Arnoult criou uma rede de amizades influente na época, logo achou necessário cursar arquitetura, onde se formou no ano de 1955 pela Faculdade Nacional do Rio de Janeiro.

Em 1954 os já sócios Arnoult e o arquiteto escocês Norman Westwater desenvolveram móveis em conjunto e apresentaram para determinadas indústrias do ramo, porém, existia ainda forte preconceito com o desenho de mobiliário moderno, visto que no mercado predominavam as mobílias de estilo, baseadas nas linhas e materiais europeus, usualmente vendidos e fabricados por nomes da época, como: Móveis Drago e Cássio Muniz.

Ainda no mesmo ano, os sócios e mais Abel de Barros Lima²ontrataram em Curitiba exfuncionários da Móveis Cimo para produzirem os protótipos e a primeira linha de móveis dos sócios, compostos por pés palitos e estantes montantes em madeira, semelhantes ao modelo da Unilabor. Logo perceberam a dimensão do mercado em que estavam se inserindo. Constituíram a Forma Móveis e Interiores LTDA, porém outra empresa já havia no momento sido registrada com tal nomenclatura. Adotaram então: Mobília Contemporânea, que ficava sediada no Paraná. (SANTOS, 1995:137)

$\mathrm{Na}$ cidade de Curitiba onde estava instalada a fábrica encontrava-se grande diversidade de madeiras de lei, principalmente Imbuia, e era o pólo industrial moveleiro da época. (MENEZES, Aureliano. 1977: 16). Em um curto tempo no mercado os sócios puderam receber um bom retorno, a mobília que desenhavam foi bem aceita pelos consumidores. Iniciaram a produção dos primeiros programas de interiores, com 35 elementos compostos por móveis modulados a preços médios que traduziam-se em funcionalidade e ao mesmo tempo organização para os ambientes que fomentavam-se através da arquitetura vertical. O sucesso do projeto aconteceu de imediato. Em São Paulo Arnoult recebia as peças de Curitiba e montava na casa dos clientes, de início a maioria eram seus colegas arquitetos que iam se casar (Revista Design \& Interior. 1992: 63).

Uma linha completa onde entravam armários, camas, sofás, mesas modulares, estantes. É nisso que consiste o pioneirismo da "Mobília Contemporânea": a modulação, móveis modernos desenhados com vistas ás novas habitações, isto é, redução de espaço e do volume, adaptado ao problema do transporte (...) nós queríamos fazer o móvel (e fizemos) como o automóvel, e os anúncios eram assim: "se quebrar uma perna, você vem e compra outra perna, não precisa chamar o marceneiro. (LIMA, 1976 apud MENEZES, 1977: 19,20).

Segundo o jornal Correio da Manhã de Fevereiro de 1956, a Mobília Contemporânea já tinha grande visibilidade na cidade de São Paulo, seu showroom inaugurou em 15 de Junho de

\footnotetext{
${ }^{2}$ Sócio de Michel Arnoult e Norman Westwater, advogado da empresa
} 
1955,e ficava localizada na Avenida Vieira de Carvalho número 19, centro refinado da capital paulista.A loja era regida pelos sócios Michel Arnoult, Norman Westwater, Abel de Barros Lima e Helena Mindlin ${ }^{3}$.

\begin{abstract}
Agora sou uma mulher de negócios. Trabalho o dia inteiro, sem parar, sem brincadeira. Nada de hobby meu caro, é trabalho sério, intenso (...) Sacrifiquei o meu apartamento e vim morar aqui no mesmo edifício da loja. Como você está vendo, o negócio é decoração de interiores. Trabalhamos em equipe, Michel Arnoult, francês, arquiteto Norman Westwater, escocês, ambos cuidando da parte de projetos e Abel de Barros Lima, advogado, brasileiro, encarregado da parte administrativa. Eu sou chefe das vendas(...) não projetamos para residências luxuosas onde o supérfluo predomina, voltando-nos, antes, para a decoração de apartamentos da classe média, esses apartamentos tão sacrificados pela especulação imobiliária e pela inércia dos arquitetos. MINDLIN, H. in JORNAL CORREIO DO AMANHÃ - São Paulo, ed.19300, ano 1956, página 12.
\end{abstract}

No mesmo ano da inauguração, 1955, a loja lançou um dos primeiros anúncios sobre móveis, contendo informações dos 33 elementos modulados que eram independentes, e tinha a relação "linha e forma". Na figura 1 é possível ver os módulos e conformidades nos ambientes, e explicando conceitos de cada uma: conforto, praticidade, harmonia, economia, flexibilidade e durabilidade. No anúncio ainda diz:

Para resolver os problemas atuais do arranjo de uma casa, Norman Westwater e Michel Arnoult criaram uma série de 33 elementos modulados independentes que obedecem a uma relação, por assim dizer "familiar", de linha e forma(...) Projetada para resolver o problema econômico, bem como o da organização do espaço, MOBÍLIA CONTEMPORÂNEA permite variações sempre novas, ambientes e arranjos mais pessoais. (LEON, 2016: 39)

Figura 1 Primeiro folheto com arranjos de ambientes da Mobília Contemporânea de 1955.

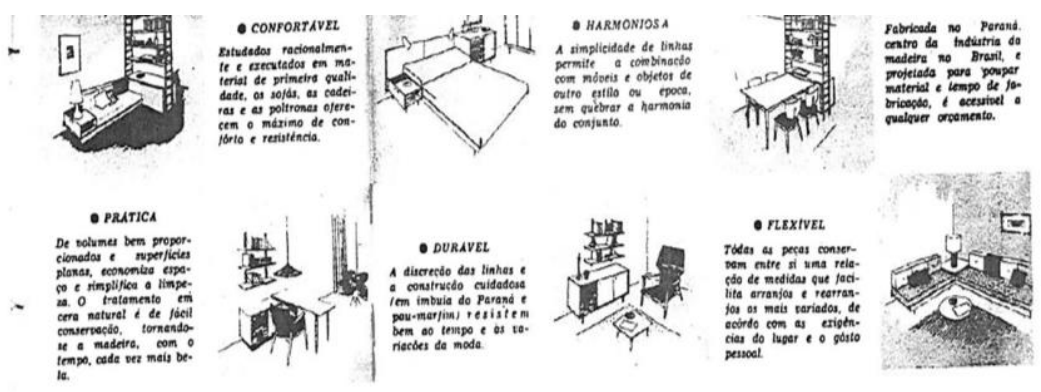

Fonte:O Móvel Moderno no Brasil (1995)

A singularidade nos móveis da MC surgiu ao se esquivarem do convencional da época; mobiliários artesanais com desenhos exclusivos e preços elevados sendo acessível apenas à consumidores abastados. Seus móveis carregavam a intenção de contribuir para a mudança do cenário de móveis no Brasil, e havia ainda a questão cultural e intelectual na qual era importante que os móveis se adequassem à industrialização e à um novo modelo de habitar. Os desenhos eram compostos por forte referência nacional, as condições de produção foram determinantes,

\footnotetext{
${ }^{3}$ Helena Mindlin na época era esposa do arquiteto Henrique Mindlin, ela entrou como sócia para contribuir com o capital inicial para poderem alugar o espaço para a primeira loja em São Paulo. (Revista Design \& Interiores, 1992: 63)
} 
principalmente a matéria prima. "Isto é diretamente ligado ao "boom" da arquitetura dos anos 30/40/50. E tinha toda uma classe média desejosa de ter um produto decente em casa a preço razoável, e nós oferecíamos isso." (ARNOULT, 1976 apud MENEZES, 1977: 16

Em 1957 a produção industrial ultrapassou a produção agrícola no Brasil, e neste momento Michel Arnoult e seus sócios introduziram-se no mercado acompanhando o processo de transição da economia, assim como a arquitetura estava passando por mudanças.

Para Arnoult e Westwater o que os levou a produzirem móveis e não fabricá-los de maneira tradicional, foi que,para os sócios, a produção em série de um mobiliário tinha a possibilidade de permanecer por mais tempo no mercado, tendo como principal visão o custo benefício dos móveis, sendo assim poderiam estocar as peças,já que haviam pensado em toda logística de armazenamento.Segundo eles, as razões para isso seriam a importância dos equipamentos industriais para o futuro, avistando também a concorrência no mercado de móveis modernos, modos de comercialização que superassem o que já estava sendo feito em produção.Todos estes fatores atrelados principalmente a qualidade do mobiliário pensando nas pequenas e médias empresas se manterem na evolução daquele cenário. Arnoult acreditava que era inadequado usa de obsolescência ou desenvolverem móveis ligados aos hábitos de esferas ricas em um país como o Brasil, com padrões de vida baixos da maioria da população (SANTOS, 1995: 137)

O momento permitia que outras empresas se solidificassem, pois a demanda do mercado proporcionava oportunidade à todos que estavam projetando móveis modernos. A filial no Rio de Janeiro, na rua dos Jangadeiros- Ipanema, localizada na Praça General Osório que também tinha aOca (Sérgio Rodrigues)e Mobilínea (Ernesto Hauner) situadas no mesmo endereço, todas elas apresentavam segmentos de móveis que podiam ser um tanto distintos, mas com desenhos análogos para finalidades comuns: alcançar a classe média e seus apartamentos de dimensões reduzidas. O local em que estavam inseridas essas lojas era rodeado por intelectuais: fotógrafos, jornalistas, músicos, logo a cultura e os modos ali fomentados se propagaram para a imprensa.

Os designers foram vanguardistas ao organizar em suas lojas showrooms com espaços domésticos modernos, em conjunto com obras modernas,com a intenção de divulgar seus projetos viabilizando a unificação das artes. A Mobília Contemporânea também seguiu uma linha de Sérgio Rodrigues na Oca, onde sediou eventos de artistas da área têxtil entre 1957 e 1958; aconteceram exposições de tapetes e mostras de padrões de tecidos desenhados por uma artista alemã. (LEON, 2016: 39).

As medidas dos módulos de $45 \mathrm{~cm}$ demonstravam nos anúncios a diversidade dos arranjos combinando as mesmas peças de variadas maneiras, que resultavam modelos de diferentes de móveis desmontáveis e funcionais para os ambientes.

Em 1959 se fez necessário uma fábrica na capital paulista, e por isso foram então instaladas duas na cidade. Desta maneira Arnoult tinha contato direto com a produção e detalhes dos móveis. Em 1960 a MC lançou a linha de mesas extensíveis, denominada como Caleidoscópio recheada de móveis auxiliares, mesinhas, tampos de mesa e portas de armários em Imbuia.

No ano seguinte, Westwater desassociou-se da Mobília Contemporânea, mudou-se para a Bahia e após algum tempo retornou ao Rio de Janeiro, retomando à loja, agora como colaborador nos projetos. Ele e Arnoult em 1963 lançaram móveis que mudaram os pés do modelo 'palito'. Adotaram desenhos torneados em conjunto de peças mais retas em madeira. Os móveis eram modulares, e a comercialização e seu modo de embalagem foram inovadores. Vendidos desmontados na loja, para o carregamento eram embalados em caixas de papelão, o que tornava 
o manuseio e transporte do mobiliário mais fácil. Fizeram parte destes modelos a cadeira e o sofá Ouro Preto, que tinham como característica a nova fase de desenhos da MC - madeira, nylon e estofado fino. Estes materiais utilizados atrelados ao desenho tornavam o móvel leve e confortável, daí surge a nomenclatura "Conforto Duro", a empresa queria hierarquizar ao mínimo seu público consumidor. A cadeira Ouro Preto, sem braços era um módulo para o sofá, podendo se transformar em sofá cama, e se adequava em qualquer ambiente; sala de jantar, quarto.

Em 1964 Michel Arnoult e Norman Westwater receberam o prêmio Roberto Simonsen, um reconhecimento pela inovação no sistema construtivo dos mobiliários que estavam produzindo.

\footnotetext{
" Concebida em termos de produção em série, trata-se de uma poltrona desmontável, com um número reduzido de elementos padronizados e compondo sua estrutura, que é perfeitamente visível e devassável. O sistema de fixação das peças componentes é simples e seguro. Destaca-se, também, a propriedade da utilização do fio de náilon como sustentação e molejo do assento e do encosto, cujas almofadas iguais, de espuma de borracha revestida de plástico (e fixadas por dois cintos de couro), podem, por essa razão, ser bastante reduzidas em sua espessura. Isso, quanto ao aspecto construtivo. Quanto aos aspectos funcionais, caracterizam-se o conforto, a leveza, e a facilidade da estrutura aberta, clara, da unidade entre o externo e o interno, da fidelidade à natureza dos materiais e de sua adequada coordenação." (SANTOS, 1995: 139)
}

Entre 1963 e 1964 a Mobília Contemporânea teve Pedro Paulo Poppovic como sócio, neste mesmo período a loja recebeu a proposta de acrescentar adornos em alguns de seus móveis, a oferta foi da Sears ${ }^{4}$. Em entrevista à Ethel Leon no ano de 2008, Poppovic disse que o argumento era: "Nós queremos um móvel que tenha riqueza. Quando a pessoa compra um móvel, há toda uma teoria psicológica envolvida, que é o retrato que as pessoas querem passar na frente. Elas querem mostrar para os outros o quanto são ricas e bem-sucedidas na vida. Elas já têm o VW, têm geladeira e agora querem ter os móveis. E os móveis têm de ser luxuosos. Afinal, o senhor, que é francês, não lembra como era Luíz XV?!." ( LEON, 2016: 46)

A Mobília Contemporânea propunha e prezava pelo requinte de acabamento, móveis bonitos e bem acabados. Em meados dos anos 1970 lançaram uma versão da Ouro Preto com braços, único caso, talvez, com um desenho com "adornos" em um móvel da MC. Os braços de madeira torneados, apoios desenhados em madeira maciça plana que se estreitavam em um desenho curvo e sutil nas áreas de junção das pernas do mobiliário. Arnoult fazia questão de não laquear a madeira para deixar seus veios a mostra, apenas tratava com óleo de linhaça natural e cera. ( LEON, 2016: 46)

A empresa como forma de expandir mais seu público potencial, em meados de 1963 criou um sistema de produção, comercialização e consumo que seguiu a $M C$ durante toda sua trajetória.Utilizou supermercados para pontos de venda de móveis embalados acompanhados de manual de instrução, o consumidor tinha a facilidade de transporte e montagem, embora a loja da MC ofertasse serviços de montagem, e também sempre manteve seu show room de escritórios e ambientes domésticos. Arnoult nunca desapegou da montagem dos ambientes em sua loja, pois era um espaço de experimentação para os clientes.

A versatilidade e polivalência dos móveis a cada ano evoluíam mais, e em 1966 lançaram um anúncio na Revista Realidade. Nele era demonstrado o móvel "sem avesso":

\footnotetext{
${ }^{4}$ Loja de departamentos que situava-se no bairro Paraíso em São Paulo
} 


\begin{abstract}
"Todos os lados, mesmo as costas, têm o mesmo acabamento. Isto significa maiores possibilidades de arranjo. Um armário como este, por exemplo, pode ser usado para dividir ambientes: almoço do lado de cá, estar do lado de lá. Quem mora em apartamento pequeno, já percebeu a vantagem."(LEON, 2016: 47)
\end{abstract}

O anúncio fazia referência à um balcão, tipo Buffet,que poderia ser utilizado em dois ambientes ao mesmo tempo; móvel solucionando o problema de espaços reduzidos e, sendo funcional para qualquer atividade.

Segundo Pedro Paulo Poppovic, Michel Arnoult acompanhava de perto a publicidade da MC, as propagandas eram minimalistas, seguiam referências concretistas em sua diagramação, fonte, palavras repetidas que podiam ser associadas aos módulos, e posicionamento de imagem estratégico. O foco sempre foi o móvel e seus atributos.

Um novo modelo de mobiliário estava surgindo no final da década de 1960, materiais como: plástico, acrílico, fibra de vidro, poliéster e polipropileno; cores quentes em objetos de decoração e utensílios domésticos. A cultura pop se manifestava e a Mobília Contemporânea seguiu os novos modelos. Lançou móveis laqueados em branco, amarelo e vermelho, os estofados passaram do neutro para o xadrez colorido. As lojas concorrentes da época: Mobilínea principalmente, que já utilizava cores em contraste com seus móveis brancos, e também Hobjeto e L'Atelier que estavam comercializando mobiliários laqueados e até com materiais sintéticos. (LEON, 2016: 49)

A Mobília Contemporânea tornou-se nacionalmente conhecida, fazia propagandas em jornais e revistas reconhecidas, como a Casa \& Jardim. Arnoult fazia questão de elaborar os anúncios e enfatizar que a montagem dos produtos teria de ser feita pelo consumidor.

Por volta 1970 foi lançada a primeira linha da Peg- Lev, móveis adaptáveis para qualquer ambiente, embrulhados em caixas de papelão para pronta entrega. Neste mesmo momento a Mobília Contemporânea incorporou em sua loja móveis de outros fabricantes, objetos de decoração e luminárias. Os móveis que eram vendidos no mercado, faziam parte da Linha C; as poltronas e sofás com braços torneados, carrinhos de chá com tampos dupla face na cor azul.

No mesmo período da década de 1970 empresas moveleiras do Sul do Brasil, em São Bento (SC) e Bento Gonçalves (RS) fortaleceram-se, e faziam parte de um mercado dinâmico e coletivo. A Mobília Contemporânea por ser uma empresa isolada, teve um resultado fraco em suas tentativas de associarem-se a outras empresas, e logo viram-se ameaçados chegando ao seu fim em 1974 . O prédio sede da loja, foi alugado pela Enciclopédia Britânia e em 1976 foi vendido para a Cebrap.

\title{
3. Análise dos Arranjos e Ambiência nos Programas de Interiores da MC
}

\subsection{O Interior Moderno e sua Conformação}

Segundo Soares (2017) o conceito de programa de necessidades é uma ferramenta para auxiliar o profissional voltado para a área de design de interiores, na produção de um ambiente coerente, segundo as instruções e informações fornecidas pelo cliente, o mesmo traçará um perfil psicológico, imaginário de sua residência, em conjunto com o conhecimento científico e técnico do designer aplicado ao espaço. É função do designer organizar espacialmente o ambiente, gerar conforto ambiental, harmonização estética, resolver a funcionalidade dos espaços, estes afetarão diretamente o usuário. Segundo a autora o designer de interiores evoluiu gradativamente; em um primeiro momento suas habilidades eram aplicadas a decoração de ambientes, em seguida ao 
desenho de mobiliários e atualmente resignifica espaços e áreas, adapta ambientes, restaura mobiliários entre outros (SOARES, 2017: 2).

Agora sobre a estrutura dos ambiente, o autor Jean Baudrillard nos diz que a configuração dos ambientes de famílias burguesas constituíam-se em áreas definidas por meio da hierarquização dos móveis - conjunto de sala de estar, conjunto de quarto de dormir. Os espaços tornavam-se unifuncionais, separados em cômodos vedados por paredes, originando espaços ornamentais. Os conjuntos eram provenientes de conceitos patriarcais, na qual existiam as tradições e a autoridade que era transmitida através do mobiliário. Os espaços burgueses não possuíam arranjos objetivos, ou seja, os móveis que habitavam o ambiente se traduziam em representar as relações humanas.

Baudrillard diz que os objetos são como deuses domésticos, repletos de memórias, portando, podem ser passados de geração para geração, conduzindo o pensamento à nostalgia. 0 autor também explica que certos móveis, ditos "móveis monumentos" (buffet, cama, armário) carregam consigo o rótulo de estar dentro de um grupo de ascensão social, sendo assim a configuração do ambiente se transpassa na estrutura familiar tradicional, presente em vasta quantidade na sociedade moderna. (BAUDRILLARD, 1968: 23).

Segundo Baudrillard o ambiente moderno sofreu mudanças em sua espacialidade e arranjo. Os armários tiveram de se adequar aos novos espaços reduzidos, enquanto através da mobília a mobilidade, a multifuncionalidade e a liberdade de organização inseriram-se fortemente dentro das moradias. É possível conceituar o mobiliário como agente definidor de funções diversas em um ambiente, e a relação entre os elementos (móveis) e o espaço geram atividades distintas.

O sistema funcional moderno aos olhos do autor, é estruturado por duas concepções; arranjo e ambiência, o primeiro consiste na organização do ambiente e sua diagramação, e o segundo no significado que os materiais e cores empregados ao móvel podem simbolizar.

As cores passaram a ser vistas de uma melhor maneira através da pintura de obras de arte, porém foi preciso um espaço de tempo para que ela se introduzisse de fato nos mobiliários, e passasse a fazer parte do cotidiano das famílias. "Poltronas vermelho vivo, divãs azul-celeste, mesas pretas: tal libertação surge fortemente ligada à ruptura de uma ordem global. É ela aliás contemporânea da libertação do objeto funcional (...)" (BAUDRILLARD, 1968: 39)

\subsection{O moderno inicial nos móveisda Mobília Contemporânea}

A Mobília Contemporânea usava como artifício de marketing,em um primeiro momento, folhetos com arranjos de ambientes como: sala estar / jantar e quarto, compostos por móveis da MC apresentados à sociedade em 1955, porém a análise do artigo será concentrada nos anúncios de 1959 e 1960 publicados na Casa \& Jardim. Mais em breve poderá ser observado que as soluções apresentadas no folheto de 1955 e os seguintes de 1959 e 1960, terão soluções de propagandas semelhantes, se guindo a mesma linha de amostras de mini ambientes.

Os móveis estampados no folheto de 1955 haviam sido desenhados e produzidos no ano anterior.

Segundo Abel de Barros, eles lançaram a primeira linha de móveis do Brasil, totalmente modulado e funcional, para que, de maneira coerente se conformassem nos ambientes projetados dos novos espaços da época. É possível observar na figura 2 que estavam presentes: camas, sofás, 
mesas modulares e estantes. Os arranjos propostos pelos sócios adequavam-se as novas maneiras de construir moradias naquela atualidade; espaços e volumes 'enxutos'.

A empresa vanguardista objetivava desde seu início a produção industrial dos mobiliários em grande escala, com qualidade e conforto. Arnoult utilizou o mesmo programa durante trinta anos, a Mobília Contemporânea não buscava lançar novidades continuamente, e sim, manter um padrão de qualidade adequado à modernidade, seguindo o mesmo conceito desde seu início. Da primeira linha, foram mantidas para seguir adiante: modulações que suprissem necessidades de casais recém casados, linha que se adequava a consultórios e também famílias pessoas solteiras,os móveis justapunham-se e casavam-se entre si. Harmonizar funcionalidade, compactação, conforto e beleza levou a Mobília Contemporânea a criar uma gama de arranjos.

“ As costas do sofá, por exemplo, tinham a mesma altura da mesa podendo, então num pequeno apartamento ou numa pequena sala, ser colocado ao lado da mesa. O mesmo acontecia com os painéis, que eram comuns ás estantes e cabeceiras." (LIMA 1976 apud MENEZES, 1977: 19)

Segundo Abel de Barros e Michel Arnoult em um depoimento, a empresa foi também uma das pioneiras ao utilizar maquetes para auxiliar a visualização dos ambientes.

Também usamos maquetes pela primeira vez. "Slogans" tipo "quem casa monta casa usando maquete" eram uma novidade incrível e hoje são muito conhecidos. Então o casal trazia a planta à loja e nós montávamos o apartamento. (...) O estudo de maquete era sempre gratuito: desenhava-se a planta baixa dos locais e entregava-se ao cliente ou então ele próprio estudava com uma pessoa adequadamente instruída. (ARNOULT \& LIMA 1976 apud MENEZES, 1977: 19)

A loja foi ganhando visibilidade e clientela, uma vez que seus programas e show rooms de ambientes tornaram-se novidade, e ao mesmo tempo, solução para diversos apartamentos.

\subsubsection{Análise dos anúncios da MC na Revista Casa \&Jardim- Edições de 1959 e 1960}

Em 1959 Michel Arnoult e sócios, lançaram a primeira página de anúncio da Mobília Contemporânea na Revista Casa \& Jardim - conceituada e popular na época.

Figura 2 Anúncio MC 1959 Casa \& Jardim
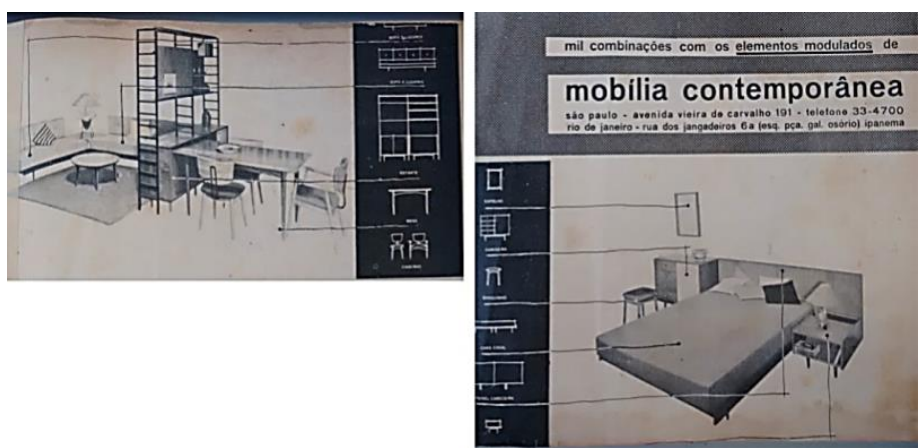

Fonte: Revista Casa e Jardim de (1959) 
Na primeira imagem da figura 2 é possível analisar a integração dos ambientes - sala de jantar e estar. A sala de estar é composta por um sofá de dois e três lugares encostados nas paredes, entre eles uma mesa baixa de canto. $O$ tapete no centro existe como delimitador da área de estar, sob ele uma mesa de centro baixa com pés palito. A estante que divide os ambientes tem um balcão linear onde a estrutura é vazada, e possivelmente ela é em ferro. Em sua continuidade há uma mesa linear composta por dois tipos de cadeira, a mesma também pode ser configurada independente da estante, transformando-se em uma mesa de seis lugares.

Este tipo de arranjo potencializa a lógica funcional do espaço em questão, e deixa o usuário a vontade para que organize e faça o melhor arranjo com os módulos tal qual necessite. Na faixa lateral da foto existe um esquema de croquis explicativo, indicando os móveis que estão compondo os ambientes.

Martine Joly fala sobre o método de permutação para analisar uma imagem e, distinguir seus diferentes componentes, porém, a autora diz que é preciso ter em mente elementos similares e substituíveis que não precisam necessariamente estar presente na imagem. Este tipo de análise faz com que enxerguemos o óbvio; o que a imagem nos mostra, mas também insinua que possamos projetar um outro ambiente em nossa mente com elementos que não estão sendo mostrados naquele contexto. A MC, com seus módulos, apresentava esta opção ao público: diversificar os ambientes. (JOLY, 1994: 57,58).

No dormitório os fundos da cama são revestidos de um painel horizontal em madeira dividido em duas partes. Na lateral direita um criado mudo baixo com pés palito, na lateral esquerda uma camiseira com mesmo tipo de pé e usos diferentes: cômoda, criado mudo e penteadeira, visto que existe um espelho logo acima dela, e um banquinho - dividida em duas partes: quatro gavetas em uma parte, e um armário vertical na outra metade. Pode-se tirar como conclusão que este eixo é livre para conformar-se em função das necessidades do usuário, as peças são modulares e permitem este tipo de flexibilização.Neste anúncio não é possível identificar o uso de cores na decoração dos ambientes, e tons de madeira por conta do anúncio ser em preto e branco, porém, a análise pode definir que alguns móveis podem ser substituídos ou tomarem outro lugar no ambiente.

Figura 3 Anúncio MC (1959)

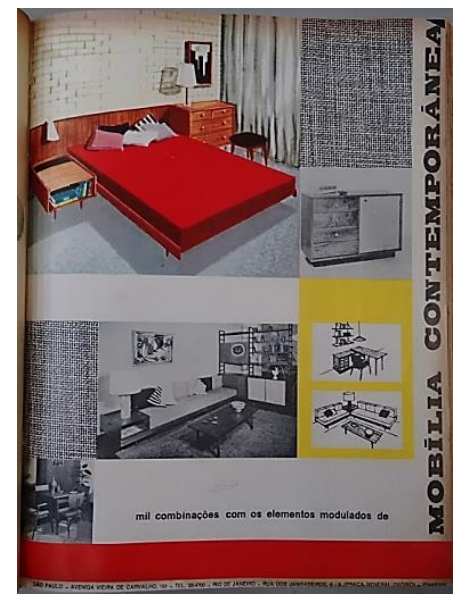

Fonte: Revista Casa \& Jardim Ed.49,51,52,54,59 
Nesta divulgação da figura 3 a empresa fez uso de cores no ambiente do dormitório, ele segue a mesma lógica funcional do primeiro anúncio: um painel linear em madeira clara com criado mudo onde é possível acomodar livros em seu vão abaixo do tampo, e seus pés são modelo palito. Na outra extremidade, a cômoda, agora apenas com gavetas; sendo duas da largura do móvel e outras duas menores. A cômoda na decoração passa a imagem de polivalência no ambiente do dormitório: 1- armazenar roupas, 2- criado mudo, uma vez que existe um abajur sob ela, e, 3- uma penteadeira, já que o banquinho e o espelho estão presentes no cenário.

Ao lado da imagem a fotografia com a opção da cômoda da figura anterior, dividida em duas partes; quatro gavetas e a outra metade um armário vertical. A cor predominante é o vermelho do colchão em contraste com a madeira clara e veios marcados, e a parede branca com cortina branca.

A segunda opção, uma imagem real de um ambiente da Mobília Contemporânea, a sala de estar. Desta vez disposta em um eixo longitudinal de sofá e mesa com mesmo desenho que o criado mudo, agora com um apoio de pé palito. O tapete delimita a área de estar, e a mesa de centro na mesma altura dos assentos do sofá e pés palito possui um desenho horizontal, o que dá a impressão de amplitude no espaço.

As duas estantes uma ao lado da outra divide os ambientes, desta vez, sua função é de uma cristaleira. Ao lado da imagem da sala, dois croquis que demonstram opções para a sala com sofás de três e quatro lugares e uma mesa no canto, a área de escritório/estudos bancada de apoio e a mesa, a mesma do primeiro anúncio que faz parte da sala de jantar, está ligada ao balcão formando um L, pendente com iluminação direcionada e prateleiras com a função de organizar verticalmente o espaço. O slogan "mil combinações com os elementos modulados" ajuda-nos a entender o conceito de "substituição" dentro do ambiente.As configurações de espaços diferentes que podem ser criados através da nossa imaginação ao observar a imagem e os mobiliários.

Figura 4 Anúncio MC (1959)

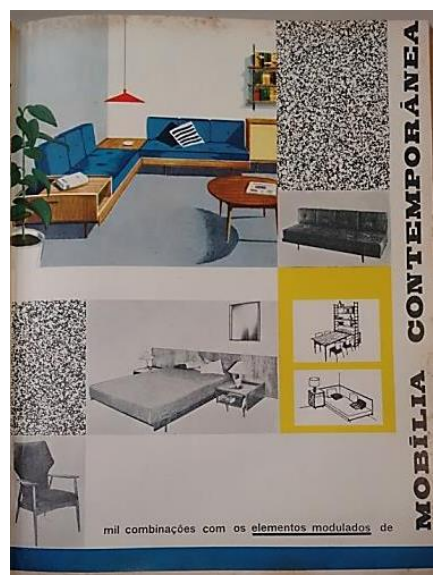

Fonte: Revista Casa \& Jardim Ed. 53, e 55

Nestas duas edições o foco foi a sala de estar, com diferencial no estofamento azul dos sofás, em conjunto com a madeira clara com veios marcados. Desta vez sofás de três lugares, canto com apoio da mesma altura que o sofá, e a mesa com mesmo desenho que o criado mudo com apoio de pé palito. $O$ tapete não foi posto em cena, apenas uma mesa central circular com pés altos modelo palito. É possível observar que existe também no ambiente uma estante de três 
prateleiras no canto direito da imagem, possivelmente de uma área de estudos como a que foi mostrada no anúncio anterior em um dos desenhos pequenos. Observa-se também uma luminária pendente na área de estar que proporciona foco de luz para quem está sentado naquele canto. Pode-se entender que os ambientes:integrados, sala e área de estudo/ escritório,ou seja,uma área reduzida transformada em micro-ambientes com diferentes funções. As cores e materiais utilizados nos micro-ambientes sinalizam a demonstração de um ambiente moderno, evoluído e liberto das questões fechadas da ambiência burguesa, como:contraste do estofado azul com a madeira mostrando seus veios na estrutura do móvel, o fechamento em madeira amarela do buffet contrasta com a parede branca, o pendente vermelho pontua sua iluminação em um espaço mais íntimo e ao mesmo tempo aberto para os outros ambientes, e as folhagens tornam de fato os espaços vivos e que dialogam entre si através de seus arranjos e conformação.

"A cor viva é sempre vivida como sinal de emancipação: de fato compensa frequentemente a ausência de qualidades mais fundamentais ( em particular a falta de espaço). A discriminação é clara: ligada ao domínio primário, aos objetos funcionais e às matérias sintéticas, as cores vivas, "vulgares", predominarão nos interiores de série. Participam assim da mesma ambiguidade que o objeto funcional" (BAUDRILLARD,1968:39). Os ambientes retratados no anúncio mostram claramente esta passagem de Baudrillard em "O Sistema dos Objetos", o uso de "cor viva" que compensa a falta de espaço: realidade imobiliária vivida na época, e também a identidade de cores posta aos objetos funcionais e interiores formados por móveis em série, logo, as cores nos remetem as cores utilizadas em móveis produzidos na escola Bauhaus.

A figura ao lado, mostra uma fotografia de menor tamanho de um sofá de quatro lugares com um material que remete ao couro, que pode substituir o sofá de três lugares conforme a utilidade do espaço e acomodações necessárias.

Em seguida temos a imagem do dormitório, sua conformação acontece da mesma maneira que os outros anúncios, painel linear, porém desta vez com dois criados mudos idênticos nos dois lados da cama, e mais uma vez o espelho aparece, deixando em aberto a opção de substituir um criado mudo por uma cômoda. Ao lado duas figuras: sala de jantar com a mesa dando continuidade ao balcão da estante mais quatro cadeiras, e uma sala com sofá cama e criado mudo.

Logo abaixo a imagem de uma cadeira estofada com braços, elas poderiam ser utilizadas na sala de jantar, como também no escritório, projetadas para serem confortáveis em ambas as funções.Os mesmos módulos recebendo usos e configurando ambientes de diferentes maneiras.

Na edição 56 do ano 1959 (figura 6), a Mobília Contemporânea incorporou o uso de fotografias reais de ambiente, sendo a primeira a sala de estar nesta revista com uso de mesa, uma cadeira com braços e um amplo tapete. A estante divide o ambiente, e logo ao lado a imagem de um sofá de três lugares com mesa lateral embutida, dando a opção para liberdade de substituição ou incorporação do móvel ao ambiente.

Abaixo a fotografia de um conjunto de cadeiras sem braços, e mesa, a mesma da foto anterior. Ao lado imagens de dois espaços, o primeiro uma área de estar, com um balcão com gaveteiro e porta - o que foi usado na área de escritório para apoio da bancada, as três prateleiras, uma poltrona de descanso aparece pela primeira vez nos anúncios e, por fim, uma mesa baixa redonda de centro. Este ambiente aparenta ser uma área para leitura e relaxamento. Logo abaixo o sofá cama junto do criado mudo. Opções e ideias para diferentes tipos de famílias e necessidades para o mesmo espaço; sala de jantar, estar/leitura ou até mesmo uma espaço onde o sofá pode aumentar para ocasiões de visita. 


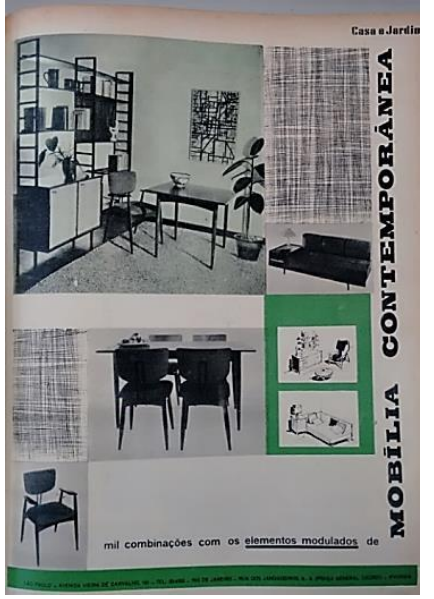

Fonte: Revista Casa \& Jardim Ed. 56

Na edição 57 (figura 6) um dos focos maiores é a estante com balcão tendo também como função apoio para uma bancada - formando uma área de estudos/escritório. Ao lado a imagem do sofá com braço nas duas extremidades podendo compor o ambiente de estudos ou a sala de estar, logo que, a bancada que forma a mesa é móvel, assim como o balcão da estante que aparece na imagem seguinte sendo uma peça única e independente, assemelha-se a um buffet composto por quatro gavetas e duas portas. Nas figuras laterais um dormitório seguindo a mesma configuração dos anúncios anteriores: criado mudo, painel, cômoda/penteadeira. A sala composta por dois sofás e a mesinha lateral entre eles, a mesa central retangular delimita o espaço desta vez. A fotografia seguinte da estante é mostrada com um balcão diferente da anterior, agora, com três portas, deixando livre para o cliente escolher opções que mais se adequem às necessidades de armazenamento. Baudrillard diz que o "conjunto moderno em série é desestruturado, mas não reestruturado." Ele têm a liberdade de estruturar-se abertamente nos ambientes, porém, desestruturado no sentido de, os mobiliários possuírem funções polivalentes. (BAUDRILLARD, 1968: 24, 25). 


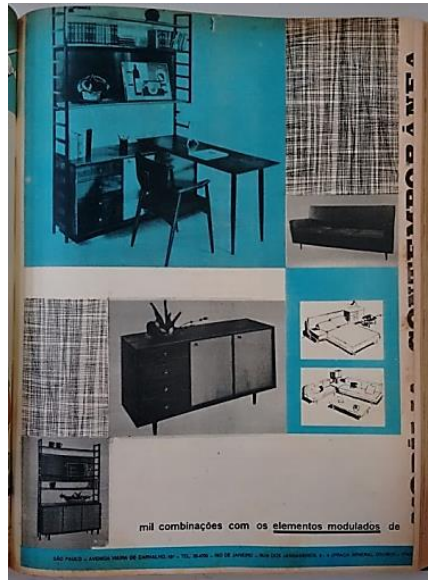

Fonte: Revista Casa \& Jardim Ed. 57

A página do anúncio da Linha Caleidoscópio das edições 63 e 64 de 1960 teve seu layout modificado e faz referência ao mesmo conceito, pelo fato da possibilidade de combinações diversas de arranjos, específica para salas de estar, jantar, dormitório e biblioteca.O croqui ao lado demonstra uma sala de estar com uso de mesa de apoio lateral, mesa central com desenho hexagonal, um pendente pontuando a iluminação, sofás de linhas simples e a estante polivalente com seus balcões. Pode-se perceber que o anúncio tornou-se minimalista, mostrando apenas a imagem das figuras diversas que um caleidoscópio nos possibilita enxergar, em conjunto com um pequeno croqui de um ambiente.

Figura 7Anúncio MC (1960)

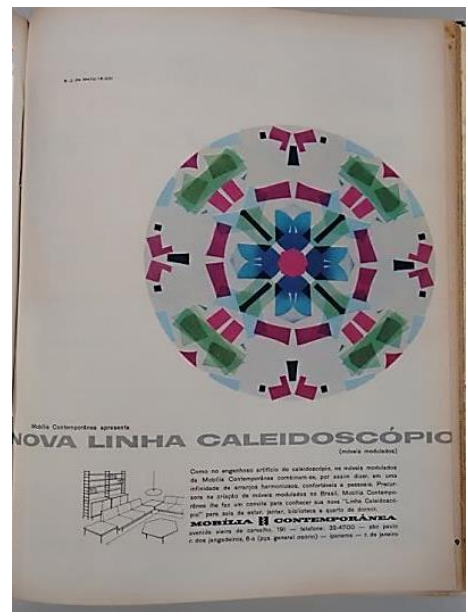

Fonte: Revista Casa \& Jardim Ed. 63 e 64

Em nenhuma imagem nos anúncios da Mobília Contemporânea foi visto o uso de paredes separando os ambientes, entende-se que este elemento presente nos interiores tradicionais, tidos como espaços- refúgios passaram a ser desvalorizados nos ambientes modernos. Os apartamentos compartilham espaços, abrem-se para diversas atividades, e os móveis tomam a liberdade de setorizar estes espaços. (BAUDRILLARD, 1968: 27) 


\section{Considerações Finais}

Os anúncios da Mobília Contemporânea tinham como intenção demonstrar às pessoas as inúmeras formas de como organizar as moradias modernas. A loja recebeu grande reconhecimento na época, participava de amostras de show rooms em conjunto com outras empresas renomadas do mesmo segmento, todas carregavam em seus trabalhos a intenção de disseminar o móvel em série industrializado de qualidade, e acessível a certas camadas sociais da classe média e também apresentar o novo estilo de vida moderno. A consolidação da Mobília Contemporânea ocorreu através da parceria e ideias compatíveis entre Michel Arnoult e Norman Westwater. Eles enxergavam a frente modos de habitar,transformar e potencializar a polivalência dos ambientes, acreditavam que os desenhos de mobiliários idealizados por eles, era possível ser acessível e produzido em série industrialmente.

O sistema de arranjos e ambiência estudados em "O Sistema dos Objetos" de Jean Baudrillard esclareceu a estratégia dos recortes de anúncios pela Mobília Contemporânea utilizados neste artigo. Seus conceitos foram empregados nos ambientes de maneira nítida; a modulação e multifuncionalidade dos móveis em conjunto com as cores, compensavam a falta de espaço nas moradias da época.

A composição da página de anúncios, com micro- ambientes, orienta o leitor e ao cliente potencial as variadas possibilidades que seus móveis carregavam (JOLY, 1996), onde utiliza o método de permutação para criar opções de novos ambientes, sendo explícita a ferramenta nas edições publicadas pela MC. Já nos recortes analisados é notável a não utilização de objetos decorativos supérfluos dentro do contexto moderno, que tinha como foco a funcionalidade dos espaços. As propagandas antes de serem publicadas passavam pelo crivo de Michel Arnoult, só eram apresentados elementos que tivessem real necessidade para tal ambiente, dando maior evidência ao mobiliário desenhado por eles, visando sempre explorar ao máximo seu potencial.

A análise da trajetória da Mobília Contemporânea em conjunto com a análise dos anúncios da revista Casa \& Jardim, permite entender como o mobiliário era articulado na propaganda para atingir o público que Michel Arnoult e sócios queriam desde o início da empresa. A Mobília Contemporânea permaneceu no mercado durante vinte anos, sempre leal aos seus ideais de produzir e vender móveis de maneira eficiente, de qualidade e duráveis.

\section{Referências}

BAUDRILLARD, Jean. O Sistema dos Objetos. São Paulo: Perspectiva, 1968.

JOLY, Martine. Introdução à Análise da Imagem. Campinas, São Paulo: Papirus, 1996.

HUGERTH, Mina Warchavichik. Mobilínea: Design de um Estilo de Vida (1959-1975). São Paulo: USP, 2015.

SANTOS, Maria Cesília Loschiavo dos. O Móvel Moderno no Brasil. São Paulo: Olhares, 1995

MENEZES, Aureliano. A Situação do Móvel no Brasil: Do projeto à Implantação Industrial ( Anos 40 aos dias atuais). São Paulo: USP, 1977

LEON, Ethel. Michel Arnoult Design e Utopia: Móveis em Série para Todos. São Paulo: Sesc, 2016. LEON, Ethel. Arnoult, o estrategista da produção seriada. In Revista Design \& Interiores, no 21. São Paulo. 1990. p.62-69.

Soares, Rosangela Carneiro. Design de Interiores focado no Cliente: definição do programa de necessidades. Revista Especialize On-line IPOG - Goiânia - Ano 8, Edição no 14 Vol. 01 dezembro/2017 